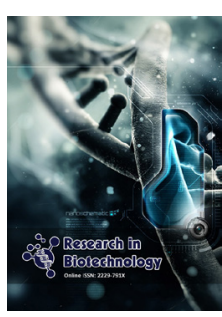

ISSN: 2229-791X

Received: July 2, 2018 Accepted: August 26, 2018

*Corresponding Author: Masnindah Malahubban Email:masnindah@upm.edu.my

\section{Antibacterial potential of methanolic and hexanic extracts of mud lobster (Thalassina anomala) from Bintulu, Sarawak, Malaysia}

\author{
Nor Hafishah Md Zohir', Masnindah Malahubban²*, Zakry Fitri Ab Aziz', \\ Amy Halimah Rajaee ${ }^{2}$ \\ ${ }^{1}$ Department of Crop Science, ${ }^{2}$ Department of Animal Science and Fisheries, Faculty of Agriculture and Food \\ Sciences, Universiti Putra Malaysia Bintulu Campus Sarawak, 97008 Bintulu, Sarawak, Malaysia
}

\begin{abstract}
Present study demonstrated the antibacterial potential of three different body parts, abdomen, carapace and cheliped of mud lobster (Thalassina anomala) which were extracted with methanol and hexane. Three test bacteria were used in this study namely Bacillus cereus, Escherichia coli, and Salmonella enterica. Present study found that in general, methanolic and hexane extracts of different body parts had variable inhibitory responses on different test bacteria with methanolic extract had greater inhibitory response than hexane extract. In methanol extraction, B. cereus significantly had greatest negative impact $(p<0.05)$ on growth after treated with cheliped $(21 \mathrm{~mm}$ zone of inhibition) extract of mud lobster as compared to carapace $(9.2 \mathrm{~mm})$ and abdominal $(8.8 \mathrm{~mm})$ extracts of mud lobster. Overall, the growth of $S$. enterica was much affected with the presence of all methanolic body-part extracts of mud lobster. In hexane extraction, B. cereus growth was not affected with all body-part extracts of mud lobster. However, E. coli and S. enterica were affected with no significantly different $(p>0.05)$ among body-part extracts and between them. Present study concludes that the extracts of mud lobster of all body-part in methanol possess greater inhibitory effect on bacterial growth than extracts in hexane thus the methanolic extract of mud lobster has the potential to be exploited as a natural source of antibacterial agent.
\end{abstract}

KEYWORDS: Antibacterial; hexane; methanol; mud lobster; Thalassina anomala

\section{INTRODUCTION}

Mud lobster, Thalassina anomala or locally known in Malaysia as "ketam busut" or "udang ketak" is recognized according to their mound made in mangrove area. The mound is built by burrowing the muddy soil using their appendages to seek food and their behaviour in destroying the apical plant shoots has classify this mud lobster as pest [1]. The crustaceans of mud lobster are included in marine organisms that have great potential in natural antibacterial sources $[2,3]$. Astaxanthin in crustacean is widely investigated and used in several applications such as in pharmaceuticals, chemicals, food and animal feed [4]. It has strong antioxidant activity presence in eggs and body tissue of crustaceans [5]. Several communities in Southeast Asia believed that the boiled $T$. anomala could potentially reduce asthmatic problem [1]. The asthmatic potential might be associated with the antioxidant properties that can be extracted from the crustacean T. anomala. Several recent studies demonstrated the plausible link between antioxidant and anti-asthmatic potential $[6,7,8]$. Extracts from several crustacean species have shown to exhibit antibacterial properties $[9,10,11]$ also Karimzadeh and Pormehr [11] reported that the prawn shell extracts could inhibit the growth of pathogenic Bacillus subtilis, Staphylococcus aureus, and Vibrio cholera and relate the activity to carotenoids content in prawn shell. Antibacterial potential from different body-part of crustacean may be important for investigation and may express different responses as demonstrated in mud crabs [12]. To the best of our information, no literature is available on the antibacterial potential of Thalassina species. Therefore, present study was conducted to assess the three bodypart of mud lobster (Thalassina anomala) namely carapace, cheliped and abdomen and extracted each with methanol and hexane and then exposed to test bacteria for antibacterial potential.

\section{MATERIALS AND METHODS}

Species of mud lobster, Thalassina anomala (Figure 1) was collected at Kuala Tatau, Bintulu, Sarawak, Malaysia $\left(3^{\circ} 4^{\prime}\right.$ $\left.24.46^{\prime \prime} \mathrm{N} ; 112^{\circ} 48^{\prime} 30.99^{\prime \prime} \mathrm{E}\right)$. The collection was rinsed by running tap water to remove any dirt materials. The samples were kept in the freezer $-4^{\circ} \mathrm{C}$ to preserve the mud lobster until further use. At sample processing, the sample was thawed in room temperature for 4 hours then washed with tap water

This article is open access and licensed under the terms of the Creative Commons Attribution License (http://creativecommons.org/licenses/by/4.0/) which permits unrestricted, use, distribution and reproduction in any medium, or format for any purpose, even commercially provided the work is properly cited. Attribution - You must give appropriate credit, provide a link to the license, and indicate if changes were made. 


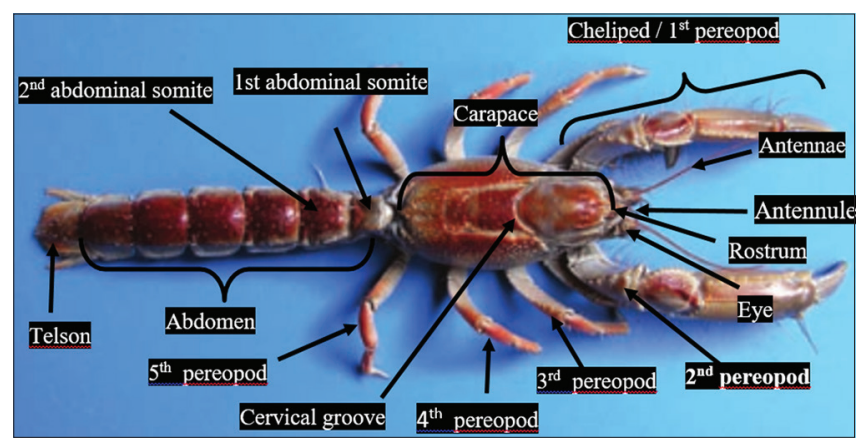

Figure 1: Thalassina anomala in Kuala Tatau, Bintulu, Sarawak, Malaysia.

The part of carapace, cheliped and abdomen were divided and wrapped in aluminium foil. Then, the samples were put in the oven and dried at $50^{\circ} \mathrm{C}$ for two weeks. The weight of sample was taken every day and stop until constant weight achieved. The dried samples were ground and homogenized using an industrial grinder $(650 \mathrm{~W}, 28000 \mathrm{rpm})$ to fine powder form. Each part of T. anomala were extracted with methanol and hexane as a solvent by using 2:5 ratio and vortexed for 30 seconds. Then, samples were placed in $50^{\circ} \mathrm{C}$ water bath for 10 minutes before centrifuged (Bench Top Centrifuge ROTINA-38) for $3000 \mathrm{rpm}$ for 10 minutes. Aqueous and organic layers were separated with new Falcon tube and fresh solvent was added until the aqueous layer become colourless. The concentrated extracts were transferred into sterile Eppendorf or $15 \mathrm{~mL}$ Falcon tube. Then, the sample was stored in $-4^{\circ} \mathrm{C}$ to reduce any contamination and degradation of bioactive compound [13].

The extracts were tested against pure culture of potential pathogenic bacteria obtained from the Culture Collection of Laboratory of Microbiology and Plant Pathology, Department of Crop Science, Faculty of Agriculture and Food Sciences, Universiti Putra Malaysia Bintulu Sarawak Campus. Three species of bacteria were used as test organism including two Gram-negative bacteria: Escherichia coli and Salmonella enterica; and a Gram-positive bacterium, Bacillus cereus, all cultures were maintained in nutrient agar medium. MuellerHinton Agar (MHA) was used in disc diffusion method to determine antibacterial activity by measuring the diameter of inhibition zone. Under aseptic condition, $100 \mu \mathrm{L}$ of bacteria from broth culture was pipetted onto MHA plates. The bacteria were spread evenly on surface of the agar using sterile hockey stick. The $25 \mu \mathrm{L}$ from each crude extraction was pipette onto Whatman No. 1 filter sterile paper disc with $6 \mathrm{~mm}$ diameter and let it dried for a while. Then, the paper disc was impregnated on the spread plate of bacteria with sterile forceps. The agar plates were kept at room temperature for 15 minutes to allow the extract on disc to absorb into agar before incubation at $37^{\circ} \mathrm{C}$ for 18 to 24 hours. Then, the tetracycline (30 $\mu \mathrm{g}$ per disc) and $10 \%$ of acetic acid were used as positive controls. Treatments were assigned in completely randomized design under laboratory condition. The antibacterial activity determined after incubation by the diameter of the inhibition zone formed around the disc. The inhibition of $T$. anomala extracted with methanol and hexane were compared with positive controls. The examination was observed as for resistant $(<7 \mathrm{~mm}$ inhibition zone) and inhibition (intermediate inhibition: 7-10 mm; moderate inhibition: 11-15 mm; strong inhibition: 16-20 mm) [13]. All data were analysed for variance and compare means by Duncan New Multiple Range Test (DNMRT) using Statistical Analysis Software (SAS) version 9.4. The results were expressed as mean milimeter diameter \pm standard error $(\mathrm{mm} \pm \mathrm{SE})$.

\section{RESULTS AND DISCUSSION}

There were significance differences $(p<0.05)$ among three different body-part extracts of mud lobster (T. anomala) with the greatest inhibition was observed on cheliped extract $(21.0 \mathrm{~mm})$ against $B$. cereus and the lowest inhibition was found on carapace $(9.2 \mathrm{~mm})$ and abdominal $(8.8 \mathrm{~mm})$ extracts (Table 1). The antibacterial potential of cheliped extract against B. cereus was comparable $(p>0.05)$ with acetic acid $(18.0 \mathrm{~mm})$ and significantly $(p<0.05)$ higher than tetracycline $(13.2 \mathrm{~mm})$. This phenomenon was found differently on E. coli where abdominal extract $(21.2 \mathrm{~mm})$ of mud lobster was at greatest as compared to cheliped $(13.2 \mathrm{~mm})$ and carapace $(10.0 \mathrm{~mm})$ extracts. This indicates that each part of the body has different chemical composition as reported by Boßelmann and co-workers [14] that American lobster Homarus americanus and the edible crab Cancer pagurus have different chemical composition in different parts of skeleton and also between two species. The difference affects its interactions with other organisms such as microbial communities [15].

The effect of abdominal extract against E. coli was no different significantly $(p>0.05)$ between acetic acid $(22.8 \mathrm{~mm})$ and tetracycline $(15.8 \mathrm{~mm})$. Among body-part extracts of mud lobster on $S$. enterica, there were no significance difference $(p>0.05)$. However, there were significance difference $(p<0.05)$ when compare with positive controls, tetracycline and acetic acid. The extracts from abdomen and cheliped were no significant different with acetic acid with considerably higher inhibition level while carapace extract and tetracycline were similar and considerably lower inhibition level. In the antibacterial potential among organisms, abdominal extract showed strongest inhibition on E. coli and S. enterica and the weakest when against B. cereus. Carapace extract against $S$. enterica was at greatest inhibition (significant different, $p<0.05$ ) as compared to B. cereus and E. coli. Cheliped extract had significantly higher inhibitory effect against B. cereus and S. enterica as compared to E. coli. Among organisms, the inhibitory effects were comparable with tetracycline and acetic acid.

Table 2 shows the different body-part of mud lobster extracted by hexane on antibacterial activity. Present study found that the growth of B. cereus was not affected by any mud lobster body-part hexane extracts. However, the growth of E. coli and S. enterica were mildly inhibited by the all body-part of hexane extracts as compared to higher inhibition zone as recorded in tetracycline and acetic acid.

When compared among test organisms, S. enterica was significantly $(p<0.05)$ differed when exposed with hexanic 
Table 1: Antibacterial potential of methanolic extracts of different body-part of Thalassina anomala

\begin{tabular}{|c|c|c|c|c|c|}
\hline \multirow[t]{2}{*}{ Test organisms } & \multicolumn{5}{|c|}{ Zone of inhibition $(\mathrm{mm} \pm \mathrm{SE})$} \\
\hline & Abdomen & Carapace & Cheliped & Tetracycline & Acetic acid \\
\hline Bacillus cereus & $8.8 \pm 0.6^{g, t}$ & $9.2 \pm 0.4^{\mathrm{fg}, \mathrm{tu}}$ & $21.0 \pm 0.5^{\mathrm{abc}, \mathrm{xyz}}$ & $13.2 \pm 2.0^{\text {defg, tuvw }}$ & $18.0 \pm 0.5^{b c d, w x y}$ \\
\hline Escherichia coli & $21.2 \pm 2.0^{\mathrm{abc}, x y z}$ & $10.0 \pm 1.6^{\text {efg,tuv }}$ & $13.2 \pm 2.8^{\text {defg, tuvw }}$ & $15.8 \pm 1.6^{\mathrm{cde}, \mathrm{wwx}}$ & $22.8 \pm 2.9^{a b, y z}$ \\
\hline Salmonella enterica & $19.0 \pm 2.4^{\mathrm{abcd}, w x y z}$ & $16.8 \pm 2.6^{c d, w x}$ & $21.4 \pm 2.1^{\mathrm{abc}, \mathrm{xyz}}$ & $14.8 \pm 1.4^{\text {def, uww }}$ & $24 \cdot 0 \pm 1.1^{\mathrm{a}, \mathrm{z}}$ \\
\hline
\end{tabular}

Means with different superscript letters $(a-g)$ within the same row differ significantly $(p<0.05)$. Means with different superscript letters ( $t-z)$ within the same column differ significantly $(p<0.05)$. Tetracycline $=30 \mu \mathrm{g} /$ disc and Acetic acid $=10 \%$ served as positive controls. Standard of error $=\mathrm{SE}$

Table 2: Antibacterial potential of hexanic extracts of different body-part of Thalassina anomala

\begin{tabular}{|c|c|c|c|c|c|}
\hline \multirow[t]{2}{*}{ Test organisms } & \multicolumn{5}{|c|}{ Zone of inhibition ( $\mathrm{mm} \pm \mathrm{SE}$ ) } \\
\hline & Abdomen & Carapace & Cheliped & Tetracycline & Acetic acid \\
\hline Bacillus cereus & n.d. & n.d. & n.d. & $13.2^{c, x} \pm 1.96$ & $18.0^{b, y} \pm 0.46$ \\
\hline Escherichia coli & $8.0^{\mathrm{de}, \mathrm{w}_{ \pm} \pm 0.32}$ & $7.2^{\mathrm{e}, \mathrm{v}} \pm 0.2$ & $7.4^{\mathrm{e}, \mathrm{v}} \pm 0.24$ & $15.8^{b c, x y} \pm 1.56$ & $22.8^{a, z} \pm 2.89$ \\
\hline Salmonella enterica & $8.0^{\mathrm{de}, \mathrm{ww}_{ \pm} \pm 0.45}$ & $8.0^{\mathrm{de}, \mathrm{vw}_{\mathrm{w}}} \pm 0.73$ & $12.0^{c d, w x} \pm 2.59$ & $14.8^{b c, x y} \pm 1.39$ & $24.0^{a, z} \pm 1.14$ \\
\hline
\end{tabular}

Means with different superscript letters $(a-f)$ within the same row differ significantly $(p<0.05)$. Means with different superscript letters $(u-z)$ within the same column differ significantly $(p<0.05)$. Positive Controls: Tetracycline: $30 \mu \mathrm{g} / \mathrm{disc}$; Acetic acid: $10 \%$; Not detected=n.d

extract of cheliped as compared to E. coli and B. cereus. A comparison between methanol and hexane extraction indicating that the methanol exhibited stronger inhibition than hexane. This is in agreement with Kiran et al. [1] which reported that the methanol extraction of several sea invertebrates were higher in antibacterial activity as compared to water extraction. Hexane extraction in most biological compounds exerted weakness in almost all biological activities such as antioxidant, antimicrobial, and anticancer $[16,17]$. This suggests that the polarity is an important aspect to improve the effectiveness of beneficial chemical composition found in the extract such as in this study, polar of methanol and non-polar of hexane where demonstrated greater and weaker activities, respectively. The antibacterial responses as shown in this study may have an association with the metabolite that can be found in the mud lobster extracts that affects or inhibits the growth of microorganisms as shown by Laith et al. [12] that relate the metabolite from whole mud crabs methanolic extract which possess antibacterial activity.

\section{CONCLUSION}

In conclusion, this study indicates the antibacterial potential in different body-part of mud lobster, Thalassina anomala. The highest potential antibacterial was found at methanolic cheliped extract. Escherichia coli and Salmonella enterica were considerably much affected with the extracts as in hexane or methanol with the latter much stronger. Thus, mud lobster (Thalassina anomala) extract has the potential as a natural antibacterial agent.

\section{ACKNOWLEDGEMENTS}

Authors wish to thank Ministry of Higher Education Malaysia for financial support through Fundamental Research Grant Scheme (FRGS/1/2015/WAB1 1/UPM/02/3) and Universiti Putra Malaysia for overall support.

\section{REFERENCES}

1. Hassan M, Lian CJ, Zakariah MI, Azmi M. 2015. A first report on mudlobster (Thalassina anomala) and its mound characteristics from Setiu wetland, Terengganu, Malaysia. Journal of Sustainability Science and Management. 2015;10(2):112-116.

2. Kiran N, Siddiqui G, Khan AN, Ibrar K, Tushar P. Extraction and screening of bioactive compounds with antimicrobial properties from selected species of mollusk and crustacean. Journal of Clinical and Cellular Immunology. 2014;5:1-5.

3. Oliveira M, Barreira L, Gangadhar KN, Rodrigues MJ, Santos T, Varela J, Custódio L. Natural products from marine invertebrates against Leishmania parasites: a comprehensive review. Phytochemistry Reviews. 2016;15(4):663-697.

4. Amado IR, González M, Murado MA, Vázquez JA. Shrimp wastewater as a source of astaxanthin and bioactive peptides. Journal of Chemical Technology and Biotechnology. 2016;91(3):793-805.

5. Snoeijs P, Häubner N. Astaxanthin dynamics in Baltic Sea mesozooplankton communities. Journal of Sea Research. 2014;85:131-143.

6. Bishopp A, Sathyamurthy R, Manney S, Webbster C, Krishna MT, Mansur AH. Biomarkers of oxidative stress and antioxidants in severe asthma: A prospective case-control study. Annals of Allergy, Asthma \& Immunology. 2017;118(4):445-451.

7. Gross NJ, Barnes PJ. New therapies for asthma and chronic obstructive pulmonary disease. American Journal of Respiratory and Critical Care Medicine. 2017; 195(2):159-166.

8. Provotorov VM, Budnevsky AV, Filatova YI, Perfil'eva MV. Antioxidant therapy of bronchial asthma. Klinicheskaia Meditsina. 2015;93(8):19-22.

9. Yu AQ, Shi $\mathrm{YH}$, Wang $\mathrm{Q}$. Characterisation of a novel type i crustin involved in antibacterial and antifungal responses in the red claw crayfish, Cherax quadricarinatus. Fish and Shellfish Immunology. 2016;48:30-38.

10. Wang $\mathrm{Y}$, Zhang $\mathrm{C}$, Wang $\mathrm{H}, \mathrm{Ma} \mathrm{H}$, Huang $\mathrm{YQ}$, Lu JX, Li XC, Zhang XW. Involvement of a newly identified atypical type II crustin (SpCrus5) in the antibacterial immunity of mud crab Scylla paramamosain. Fish and Shellfish Immunology. 2018;75:346-356.

11. Karimzadeh K, Pormehr M. Antibacterial activity of different extracts of prawn shell (Macrobrachium nipponense) against human bacterial pathogens. International Archives of Health Sciences. 2017;4(1):13.

12. Laith AA, Ambak M, Abol-Munafi AB, Nurhafizah WWI, Najiah M Metabolomic analysis of marine and mud crabs based on antibacterial activity. Aquaculture Reports. 2017;7:7-15.

13. Malahubban M, Alimon AR, Sazili AQ, Fakurazi S, Zakry FA. Phytochemical analysis of Andrographis paniculata and Orthosiphon stamineus leaf extracts for their antibacterial and antioxidant potential. Tropical Biomedicine. 2013;30(3):467-480.

14. Boßelmann F, Romano P, Fabritius $H$, Raabe D, Epple M. The composition of the exoskeleton of two crustacea: The American 
Zohir, et al.

lobster Homarus americanus and the edible crab Cancer pagurus. Thermochimica Acta. 2007;463(1-2):65-68.

15. Goffredi SK, Gregory A, Jones WJ, Morella NM, Sakamoto RI. Ontogenetic variation in epibiont community structure in the deepsea yeti crab, Kiwa puravida: convergence among crustaceans. Molecular Ecology. 2014;23(6):1457-1472

16. Çetin B, Kaya Y, Çakir A, Özer H, Aksakal Ö, Mete E. Antimicrobial activities of essential oils and hexane extracts of two turkish spice plants, Cymbocarpum erythraeum (DC.) Boiss. and Echinophora tenuifolia L. against foodborne microorganisms. Records of Natural Products. 2016;10(4):426.

17. Madkour HM, Ghareeb MA, Abdel-Aziz MS, Khalaf OM, Saad AM El-Ziaty AK, Abdel-Mogib M. Gas chromatography-mass spectrometry analysis, antimicrobial, anticancer and antioxidant activities of n-hexane and methylene chloride extracts from Senna italica. Journal of Applied Pharmaceutical Science. 2017;7:23-32. 